Original Research Article

\title{
Drug utilization study in ischaemic heart disease in a tertiary care hospital, Mangalore, India
}

\author{
Tittu George Zachariah ${ }^{1 *}$, Subramanyam K. ${ }^{2}$, Pooja M. ${ }^{1}$, Vinayak J. Kempaller ${ }^{3}$
}

${ }^{1}$ Department of Pharmacology, ${ }^{2}$ Department of Cardiology, ${ }^{3}$ Department of Community Medicine, K. S. Hegde Medical Academy, Mangalore,

Karnataka, India

Received: 12 May 2017

Accepted: 06 June 2017

\section{*Correspondence to:}

Dr. Tittu George Zachariah, Email: tittu327@gmail.com

Copyright: () the author(s), publisher and licensee Medip Academy. This is an openaccess article distributed under the terms of the Creative Commons Attribution NonCommercial License, which permits unrestricted noncommercial use, distribution, and reproduction in any medium, provided the original work is properly cited.

\begin{abstract}
Background: The study of drug utilization is a component of a medical audit and periodic evaluation need to be done to enable suitable modifications in prescription of drugs to increase the therapeutic benefit and decrease the adverse effects. When new drugs are used additional information on safety and efficacy may be generated. Ischaemic heart disease (IHD) is a condition in which there is an inadequate supply of blood and oxygen to a portion of the myocardium. Medications for IHD include anti-platelet therapy, nitrates, statins, ACE inhibitors, beta blockers, CCB's, diuretics.

Methods: The study was carried out at cardiology department of K. S. Hegde Charitable Hospital for a period of one year from January 2015, and relevant retrospective data were also collected from hospital records for period pertaining to one year from $1 / 1 / 2013$.

Results: We assessed discharge summaries of 950 patients and found that majority of patients were males than females. The highest number of patients were in the age group of 51-60 years. Polypharmacy has been observed in our study. The average number of days spent by the patients in the hospital was 3.5 days. None of the drugs were prescribed using generic names, all the drugs $(100 \%)$ were prescribed in brand names only. Common co-morbidities associated with IHD were hypertension and diabetes. Most commonly prescribed drugs for IHD were Aspirin, followed by Atorvastatin, Clopidogrel, and Nitrates.

Conclusions: In our study, on analysing the drug prescription data it was observed that there was no statistically significant change in drug utilization between the two years.
\end{abstract}

Keywords: Anti-platelet therapy, Drug utilisation study, Ischaemic heart disease, Polypharmacy

\section{INTRODUCTION}

In the mid-1960s due to the initiatives taken in Northern Europe and the United Kingdom, development of drug utilization research started. ${ }^{1}$ Drug utilization research was defined by WHO in 1977 as "study of the marketing, distribution, prescription, and use of drugs in a society, with special emphasis on the resulting medical, social and economic consequences". ${ }^{2}$ Mainly drug utilization studies emphasis on the factors associated with the prescribing, dispensing, administering, and taking of medication, and its associated events, covering the medical and nonmedical determinants of drug utilization, the effects of drug utilization, as well as studies of how drug utilization relates to the effects of drug use, beneficial or adverse. ${ }^{3}$ In India, many socio-cultural factors like national drug policy, illiteracy, poverty, use of multiple health care systems, drug advertising, and promotion, the sale of prescription drugs without a prescription, competition in the medical and pharmaceutical marketplace and limited availability of independent, unbiased drug information contribute to the ways drug are used. Underuse, overuse or misuse of drugs is a major problem and due to this complexity of drug use, optimal benefits of drug therapy in patient care may not be achieved. Inappropriate drug use may also lead to increased cost of medical care, antimicrobial resistance, adverse effects and patient 
mortality. So in recent years drug utilization studies have become a potential tool to be used in the evaluation of health systems. ${ }^{4}$ Irrational prescription of drugs is a common occurrence in clinical practice. Studies from both developed and developing countries describe a pattern that includes polypharmacy, the use of drugs that are not related to diagnosis or unnecessarily expensive, the inappropriate use of antibiotics and irrational self medication with drugs frequently taken in under dose. ${ }^{5}$

Ischaemic heart disease (IHD) is a condition in which there is an inadequate supply of blood and oxygen to a portion of the myocardium; it typically occurs when there is an imbalance between myocardial oxygen supply and demand. Atherosclerotic disease of an epicardial coronary artery is the most common cause of myocardial ischemia. ${ }^{6}$ Risk factors of IHD include modifiable and non-modifiable factors. Modifiable risk factors include Cigarette smoking, High blood pressure, Elevated serum cholesterol, Diabetes, Obesity, Sedentary habits, Stress. Non-modifiable risk factors include Age, Sex, Family history, Genetic factors. ${ }^{7-16}$

Symptoms of stable IHD include angina (characteristic chest pain) and decreased exercise tolerance, while unstable IHD presents itself as chest pain or other symptoms at rest, or rapidly worsening angina. Shortness of breath occurs due to the inability of the heart to pump blood according to the body's need. A heart attack occurs as a result of blocked coronary artery, signs and symptoms include crushing pressure in chest and radiation of pain to shoulder or arm, with shortness of breath and sweating, such as nausea and back or jaw pain. A heart attack can also occur without any apparent signs or symptoms. ${ }^{6}$

Diagnosis includes Baseline electrocardiography (ECG), Exercise ECG- Stress test, Exercise radioisotope test (Nuclear stress test, Myocardial Scintigraphy), Echocardiography, Coronary angiography, Intravascular ultrasound, Magnetic resonance imaging (MRI). ${ }^{6}$

Treatment options for IHD include drug therapy, Percutaneous Coronary Intervention (PCI) and Coronary Artery Bypass Grafting (CABG). The drug therapy involves the use of Statins, Nitrates, Angiotensin Converting Enzyme (ACE) inhibitors, Calcium channel blockers and Beta blockers, Aspirin, and Antiplatelet Therapy. These drugs act by decreasing the levels of blood cholesterol, decreasing the myocardial oxygen consumption, causes vasodilatation and prevents clotting of blood- thus relieving the signs and symptoms. ${ }^{17}$

Monitoring of prescriptions and drug utilization studies could recognize the associated difficulties and deliver feedbacks to the prescriber so as to create an awareness for the rational use of drugs. Therefore, this study attempts to evaluate the current utilization patterns of drugs used in the treatment of Ischaemic heart disease in order to guarantee appropriate drug use to decrease the morbidity and mortality of the disease and reduce the unnecessary economic burden on the patient. The findings of this study are believed to provide significant and useful feedback to physicians.

\section{METHODS}

The study was carried out at cardiology department of K. S. Hegde Charitable Hospital for a period of one year from January 2015. Discharge summaries of the patients were referred and following data was collected:

- The Demographic data

- Diagnosis

- Treatment given

- Duration of stay in the hospital

- Number of drugs prescribed using generic names

By analysing the above data following indicators were noted:

\section{Prescribing indicators}

1. Average number of drugs per patient was calculated (calculated by dividing the total number of different drugs given by the total number of patients)

2. Percentage of drugs prescribed by generic names (calculated by dividing the number of drugs used by generic name by the total number of drugs, multiplied by 100)

\section{Patient indicators}

1. Average age of men (determined by adding the ages of all men by the total number of men)

2. Average age of women (determined by adding the ages of all women by the total number of women)

3. Men to women ratio (determined by dividing the number of men by the number of women)

Relevant retrospective data as above were also collected from hospital records for period pertaining to one year from $1 / 1 / 2013$.

Data from both studies was analysed using descriptive and appropriate statistical methods to find any significant trends.

\section{Inclusion criteria}

Patients between 30 to 80 years of age undergoing medical treatment for Ischaemic heart diseases in K. S. Hegde Charitable Hospital.

\section{Exclusion criteria}

- Patients below 30 years of age.

- Pregnant patients.

- Patients with chronic kidney disease, malignant neoplasms or any other terminal diseases. 


\section{Statistical analysis}

Statistical Analysis was done by entering the data into Microsoft Excel spreadsheet (version 2013) and analysed using Microsoft Excel and represented as number and percentage, and the chi-square test was also performed.

\section{RESULTS}

Total 950 discharge summaries of the patients who were admitted in cardiology ward of Justice K. S. Hegde charitable hospital over a period of two years (2013 and 2015) based on specified inclusion and exclusion criteria were studied.

Table 1: Gender wise distribution of IHD.

\begin{tabular}{|llll|l|}
\hline Gender & $\mathbf{2 0 1 5}$ & $\mathbf{2 0 1 3}$ & $\begin{array}{l}\text { Total } \\
\text { number of } \\
\text { patients }\end{array}$ & Percentage \\
\hline Male & $\begin{array}{l}396 \\
(73 \%)\end{array}$ & $\begin{array}{l}311 \\
(76 \%)\end{array}$ & 707 & $74 \%$ \\
\hline Female & $\begin{array}{l}144 \\
(27 \%)\end{array}$ & $\begin{array}{l}99 \\
(24 \%)\end{array}$ & 243 & $26 \%$ \\
\hline Total & 540 & 410 & 950 & $100 \%$ \\
\hline
\end{tabular}

For 2015, of the total 540 patients, 396 (73\%) were males and $144(27 \%)$ were females, with a male: female ratio of 2.75:1 (Table 1). Highest number of patients (both males and females included) were in the age group of 51-60 years (211 patients, $39.07 \%$ ), followed by the age group of 61-70 years (144 patients, 26.67\%), 41-50 years (107 patients, $19.81 \%), 71-80$ years (50 patients, 9.26\%), 3140 years (28 patients, 5.19\%). Mean age group was around 57.26 years (Table 2).

Table 2: Age-wise distribution of IHD.

\begin{tabular}{|llll|l|}
\hline $\begin{array}{l}\text { Age in } \\
\text { years }\end{array}$ & $\mathbf{2 0 1 5}$ & $\mathbf{2 0 1 3}$ & $\begin{array}{l}\text { Total } \\
\text { number of } \\
\text { patients }\end{array}$ & Percentage \\
\hline $31-40$ & $\begin{array}{l}28 \\
(5 \%)\end{array}$ & $\begin{array}{l}22 \\
(5 \%)\end{array}$ & 50 & $5 \%$ \\
\hline $41-50$ & $\begin{array}{l}107 \\
(20 \%)\end{array}$ & $\begin{array}{l}88 \\
(22 \%)\end{array}$ & 195 & $21 \%$ \\
\hline $51-60$ & $\begin{array}{l}211 \\
(39 \%)\end{array}$ & $\begin{array}{l}161 \\
(39 \%)\end{array}$ & 372 & $39 \%$ \\
\hline $61-70$ & $\begin{array}{l}144 \\
(27 \%)\end{array}$ & $\begin{array}{l}99 \\
(24 \%)\end{array}$ & 243 & $26 \%$ \\
\hline $71-80$ & $\begin{array}{l}50 \\
(9 \%)\end{array}$ & $\begin{array}{l}40 \\
(10 \%)\end{array}$ & 90 & $9 \%$ \\
\hline Total & 540 & 410 & 950 & $100 \%$ \\
\hline
\end{tabular}

For 2013, of the total 410 patients 311 (76\%) were males and $99(24 \%)$ were females, with a male: female ratio of 3.4:1 (Table 1). Highest number of patients (both males and females included) were in the age group of 51-60 years (161 patients, 39.27\%), followed by the age group of $61-70$ years (99 patients, $24.15 \%$ ), 41-50 years (88 patients, $21.46 \%$ ), 71-80 years (40 patients, 9.76\%), 3140 years (22 patients, 5.37\%). Mean age group was around 56.93 years (Table 2). The incidence of IHD was more common in males compared to females.

Out of the 950 patients, the total number of drugs prescribed was 5625. Polypharmacy has been observed in our study. Number of drugs per prescription ranged from $1-13$ and the average number of drugs per prescription were 5.92 .

In the year 2015, number of prescriptions screened were 540 and the total number of drugs in these prescriptions were 3281 . The number of drugs per prescription ranged from 1-13 and the average number of drugs per prescription were 6.08 (Table 3 ).

\section{Table 3: Frequency of number of drugs prescribed per patient.}

\begin{tabular}{|llll|}
\hline $\begin{array}{l}\text { Number } \\
\text { of drugs } \\
\text { per } \\
\text { patient }\end{array}$ & $\begin{array}{l}\text { Frequency } \\
\text { of patients } \\
\mathbf{2 0 1 5}(\mathbf{\%})\end{array}$ & $\begin{array}{l}\text { Frequency } \\
\text { of patients } \\
\mathbf{2 0 1 3}(\%) \\
(\mathbf{n = 4 1 0 )}\end{array}$ & $\begin{array}{l}\text { Total } \\
\text { frequency } \\
\text { of patients } \\
(\%)\end{array}$ \\
\hline 1 & $6(1.1 \%)$ & $5(1.2 \%)$ & $11(1 \%)$ \\
\hline 2 & $28(5.3 \%)$ & $24(5.8 \%)$ & $52(6 \%)$ \\
\hline 4 & $39(7.2 \%)$ & $36(8.7 \%)$ & $75(8 \%)$ \\
\hline 5 & $50(9.3 \%)$ & $34(8.4 \%)$ & $84(9 \%)$ \\
\hline 6 & $68(12.7 \%)$ & $62(15.2 \%)$ & $130(14 \%)$ \\
\hline 7 & $102(18.9 \%)$ & $101(24.7 \%)$ & $203(21 \%)$ \\
\hline 8 & $129(23.8 \%)$ & $89(21.7 \%)$ & $218(23 \%)$ \\
\hline 9 & $54(10 \%)$ & $34(8.3 \%)$ & $88(9 \%)$ \\
\hline 10 & $40(7.5 \%)$ & $17(4.2 \%)$ & $57(6 \%)$ \\
\hline 11 & $16(2.9 \%)$ & $6(1.4 \%)$ & $22(2 \%)$ \\
\hline 12 & $3(0.5 \%)$ & $1(0.2 \%)$ & $4(0.4 \%)$ \\
\hline 13 & $3(0.5 \%)$ & $1(0.2 \%)$ & $4(0.4 \%)$ \\
\hline Total & $2(0.3 \%)$ & $0(0 \%)$ & $2(0.2 \%)$ \\
\hline & $540(100 \%)$ & $410(100 \%)$ & $950(100 \%)$ \\
\hline
\end{tabular}

In the year 2013, number of prescriptions screened were 410 and the total number of drugs in these prescriptions were 2344. The number of drugs per prescription ranged from 1-12 and the average number of drugs per prescription were 5.72 (Table 3 ).

Out of the 950 patients, the total number of drugs prescribed was 5625. For 2015, number of prescriptions screened were 540 and the total number of drugs in these prescriptions were 3281 . All of the drugs were prescribed in brand name $(100 \%)$, none of the drugs were prescribed in generic name. For 2013, number of prescriptions screened were 410 and the total number of drugs in these prescriptions were 2344. All of the drugs were prescribed in brand name $(100 \%)$, none of the drugs were prescribed in generic name (Figure 1).

Most common co-morbid conditions found in patients which increase the risk of IHD were hypertension (HTN) 
and diabetes mellitus (DM). The incidence of HTN was more compared to DM in patients suffering from IHD.

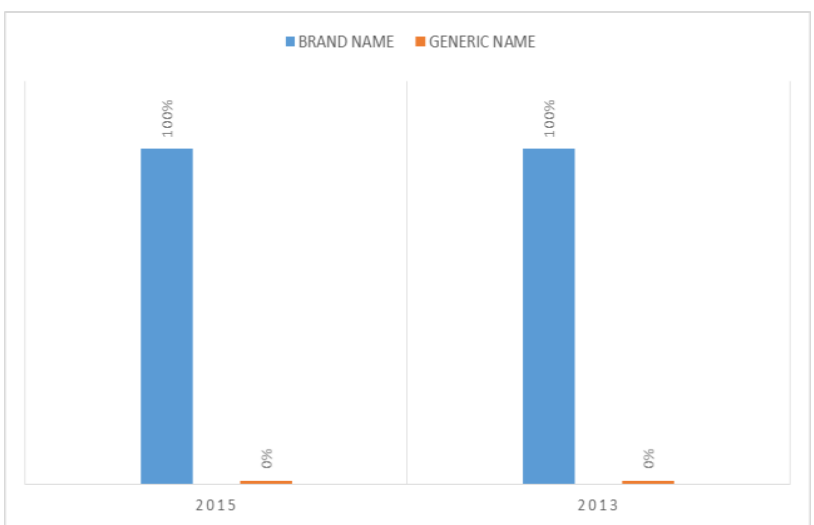

Figure 1: Brand name Vs. generic name.

For 2015 , of the total 540 patients, 168 patients $(31 \%)$ were hypertensive, 82 patients $(15 \%)$ were diabetic and 112 patients (21\%) were found to have both HTN and DM, while 178 patients (33\%) neither had HTN or DM associated with IHD (Table 4).

Table 4: Co - morbidities associated with IHD.

\begin{tabular}{|lll|}
\hline Co - morbidities & $\mathbf{2 0 1 5}(\%)$ & $\mathbf{2 0 1 3}(\%)$ \\
\hline HTN & $168(31 \%)$ & $104(25 \%)$ \\
\hline DM & $82(15 \%)$ & $65(16 \%)$ \\
\hline HTN + DM & $112(21 \%)$ & $82(20 \%)$ \\
\hline NO HTN/DM & $178(33 \%)$ & $159(39 \%)$ \\
\hline
\end{tabular}

For 2013, of the total 410 patients, 104 patients (25\%) were hypertensive, 65 patients $(16 \%)$ were diabetic and 82 patients $(20 \%)$ were found to have both HTN and DM, while 159 patients (39\%) neither had HTN or DM associated with IHD (Table 4).

Duration of stay at the hospital varied from patient to patient and their associated conditions. In the year 2015, the average number of days spent by the patients in the hospital was 3.51 and that in 2013 was 3.59 days (Figure 2).

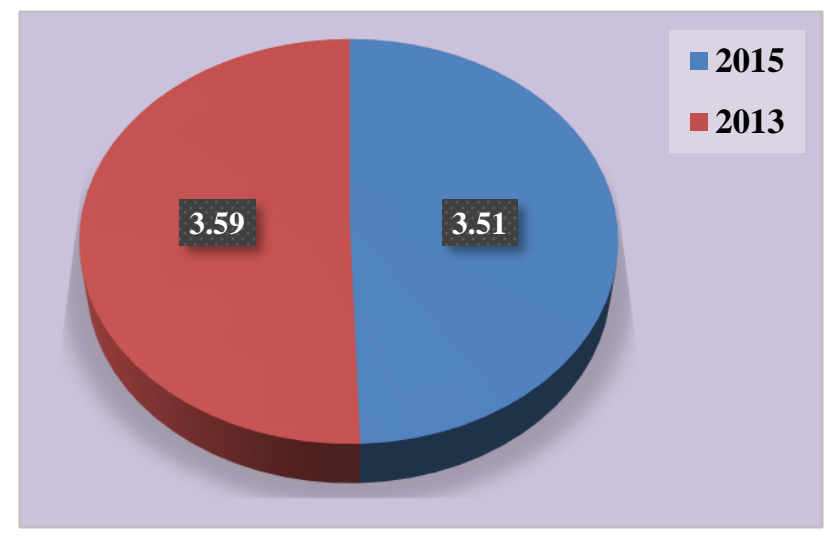

Figure 2: Duration of hospital stay.
For 2015, of the total 540 patients most commonly prescribed drugs were Aspirin (516 patients, 96\%), followed by Atorvastatin (481 patients, 89\%), Clopidogrel (408 patients, 76\%), Nitrates (395 patients, 73\%), Metoprolol (234 patients, 43\%), Amlodipine (84 patients, 16\%), Ramipril (73 patients, 14\%), Torsemide (72 patients, 13\%), Losartan (33 patients, 6\%) and, Spironolactone (31 patients, 6\%) (Table 5).

Table 5: Percentage of drugs prescribed in 2015.

\begin{tabular}{|l|l|l|}
\hline Drugs & $\begin{array}{l}\text { No. of } \\
\text { prescriptions }\end{array}$ & $\begin{array}{l}\text { Percentage } \\
\text { prescribing } \\
\text { prevalence }\end{array}$ \\
\hline Aspirin & 516 & $96 \%$ \\
\hline Atorvastatin & 481 & $89 \%$ \\
\hline Pantoprazole & 474 & $88 \%$ \\
\hline Clopidogrel & 408 & $76 \%$ \\
\hline Nitrates & 395 & $73 \%$ \\
\hline Metoprolol & 234 & $43 \%$ \\
\hline Alprazolam & 192 & $36 \%$ \\
\hline Amlodipine & 84 & $16 \%$ \\
\hline Ramipril & 73 & $14 \%$ \\
\hline Torsemide & 72 & $13 \%$ \\
\hline Losartan & 33 & $6 \%$ \\
\hline Spironolactone & 31 & $6 \%$ \\
\hline
\end{tabular}

For 2013, of the total 410 patients most commonly prescribed drugs were Aspirin (390 patients, 95\%), followed by Atorvastatin (360 patients, 88\%), Clopidogrel (298 patients, 73\%), Nitrates (295 patients, $72 \%$ ), Metoprolol (185 patients, 45\%), Amlodipine (62 patients, 15\%), Ramipril (59 patients, 14\%), Torsemide (46 patients, 11\%), Spironolactone (19 patients, 5\%) and Losartan (15 patients, 4\%) (Table 6).

Table 6: Percentage of drugs prescribed in 2013.

\begin{tabular}{|lll|}
\hline Drugs & $\begin{array}{l}\text { No. of } \\
\text { prescriptions }\end{array}$ & $\begin{array}{l}\text { Percentage } \\
\text { prescribing } \\
\text { prevalence }\end{array}$ \\
\hline Aspirin & 390 & $95 \%$ \\
\hline Atorvastatin & 360 & $88 \%$ \\
\hline Pantoprazole & 357 & $87 \%$ \\
\hline Clopidogrel & 298 & $73 \%$ \\
\hline Nitrates & 295 & $72 \%$ \\
\hline Metoprolol & 185 & $45 \%$ \\
\hline Amlodipine & 62 & $15 \%$ \\
\hline Ramipril & 59 & $14 \%$ \\
\hline Alprazolam & 59 & $14 \%$ \\
\hline Torsemide & 46 & $11 \%$ \\
\hline Spironolactone & 19 & $5 \%$ \\
\hline Losartan & 15 & $4 \%$ \\
\hline
\end{tabular}

\section{DISCUSSION}

In our study period, we assessed discharge summaries of 950 patients and found that majority of patients were 
males than females. For 2015, of the total 540 patients, $396(73 \%)$ were males and $144(27 \%)$ were females, with a male: female ratio of $2.75: 1$. For 2013, of the total 410 patients $311(76 \%)$ were males and 99 (24\%) were females, with a male: female ratio of $3.4: 1$. This is in accordance with the findings of similar studies by Dawalji et al, and Kumar et al, who reported the incidence of IHD is more in male compared to female. $^{18,19}$

In our study, we found out that highest number of patients were in 51-60 year age group followed by 61-70 year age group. Mean age group was around 57 years. For 2015, highest number of patients (both males and females included) were in the age group of 51-60 years (211 patients, $39.07 \%$ ), followed by the age group of 61 70 years (144 patients, 26.67\%), and mean age group was around 57.26 years. For 2013, highest number of patients (both males and females included) were in the age group of 51-60 years (161 patients, $39.27 \%$ ), followed by the age group of 61-70 years (99 patients, $24.15 \%$ ), and mean age group was around 56.93 years. This result is similar to a study done by George et al. ${ }^{20}$ Early age at onset of IHD has been documented as one of the unique barriers to the optimal management of IHD in India. ${ }^{21}$

Polypharmacy has been observed in our study. For 2015, number of prescriptions screened were 540 and the total number of drugs in these prescriptions were 3281. The number of drugs per prescription ranged from 1-13 and the average number of drugs per prescription were 6.08 . For 2013, number of prescriptions screened were 410 and the total number of drugs in these prescriptions were 2344. The number of drugs per prescription ranged from 1-12 and the average number of drugs per prescription were 5.72. Polypharmacy may be justified as this was a tertiary care setting where the majority of patients were hospitalized with multiple co-morbidities. This result was similar to the finding by George et al. ${ }^{20}$

Duration of stay at the hospital varied from patient to patient and their associated conditions. In our study for the year 2015, the average number of days spent by the patients in the hospital was 3.51 and that in 2013 was 3.59 days. The interplay of polypharmacy and multiple comorbidities are proven risk factors for ADRs, which significantly increase the duration of hospital stay. ${ }^{22}$

In our study, none of the drugs were prescribed using generic names, all the drugs (100\%) were prescribed in brand names only. In one study by Dawalji et al, the percentage of drugs prescribed by generic name was $2.33 \% .^{18}$

Common co-morbidities associated with IHD were hypertension and diabetes that we found in our studies. For 2015 , of the total 540 patients, 168 patients $(31 \%)$ were hypertensive, 82 patients $(15 \%)$ were diabetic and 112 patients $(21 \%)$ were found to have both HTN and DM, while 178 patients (33\%) neither had HTN or DM associated with IHD, and for 2013, of the total 410 patients, 104 patients $(25 \%)$ were hypertensive, 65 patients $(16 \%)$ were diabetic and 82 patients $(20 \%)$ were found to have both HTN and DM, while 159 patients (39\%) neither had HTN or DM associated with IHD. This result is similar to a study done by George et al. ${ }^{20}$ Prevalence of hypertension in India, for the last three decades, has increased by about 30 and 10 times among urban and rural residents respectively. ${ }^{23}$ Hypertension and diabetes mellitus are major and modifiable risk factors which when controlled can significantly reduce IHDs morbidity and mortality. ${ }^{24}$

The treatment for IHD includes drug categories such as antiplatelet drugs, antianginal drugs, anticoagulants, betablockers, calcium channel blockers, ACE inhibitors/ angiotensin II receptor blockers (ARBs), diuretics, etc. Financially developed countries have effective strategies for screening, evaluation, and management of IHD, but these strategies are not fully established in India. ${ }^{25}$ Guidelines based on evidence from randomized controlled trials recommend that aspirin, beta-adrenergic blockers, ACE inhibitors, and 3-hydroxy-3methylglutaryl-coenzyme A reductase inhibitors (statins) can be used in all patients with symptomatic chronic stable angina or asymptomatic survivors of acute myocardial infarction and following percutaneous coronary intervention or coronary bypass surgery for secondary prevention of myocardial infarction, stroke, and death. It has been postulated that if used together these agents could reduce the long-term risk of cardiovascular events and mortality by as much as $75 \% .^{26}$

In a study conducted by Banerjee $S$ et al, the commonly prescribed drugs were as follows - isosorbide mononitrate among the nitrates, clopidogrel among the antiplatelet agents, metoprolol among the beta blockers, amlodipine among the calcium channel blockers, ramipril among the ACE inhibitors, atorvastatin among the hypolipidaemic and unfractionated heparin (UFH) among the anticoagulants, while in another study by Dawalji et al, the commonly prescribed drugs were isosorbide dinitrate among the nitrates, aspirin among the antiplatelet agents, metoprolol among the beta blockers, amlodipine among the calcium channel blockers, ramipril among the ACE inhibitors, atorvastatin among the hypolipidaemic and enoxaparin among the anticoagulants. ${ }^{18,27}$

In our study the commonly prescribed drugs were isosorbide mononitrate among the nitrates, aspirin among the antiplatelet agents, metoprolol among the beta blockers, amlodipine among the calcium channel blockers, ramipril among the ACE inhibitors and atorvastatin among the hypolipidaemic.

For the year 2015 and 2013, on analysing the drug prescription data for IHD, it was observed that there was no statistically significant change in drug utilization between the two years. 


\section{CONCLUSION}

In our study, on analysing the drug prescription data it was observed that there was no statistically significant change in drug utilization between the two years. The study of drug utilization is a component of a medical audit that does monitoring and evaluation of the prescription and suggests necessary reformations to achieve rational and cost-effective medical care. The results of this study will help prescribers enhance patient management by rationalizing prescribing practices.

\section{ACKNOWLEDGMENTS}

Authors would like to express their humble gratitude to the patients who participated in the study. Also, authors are thankful to the Head of the Institution for permitting to carry out study.

Funding: No funding sources Conflict of interest: None declared

Ethical approval: The study was approved by the Institutional Ethics Committee

\section{REFERENCES}

1. Wiholm BE, Westerholm B. Drug utilization and morbidity statistics for the evaluation of drug safety in Sweden. Acta Med Scand Suppl. 1984;683:10717.

2. WHO Int WG for Drug Statistics Methodology. Introduction to Drug Utilization Research. Solutions. 2003;1-48.

3. Strom BL, Kimmel SE, Hennessy S. Pharmacoepidemiology, $5^{\text {th }}$ Edition; 2012:1-953.

4. Laporte J, Porta M, Capella D. Drug utilization studies: a tool for determining the effectiveness of drug use. Br J Clin Pharmacol. 1983;16(3):301-4.

5. Hogerzeil HV. Promoting rational prescribing: an international perspective. $\mathrm{Br} \mathrm{J}$ Clin Pharmacol. 1995;39(1):1-6.

6. Antman EM, Andrew P, Selwyn JL. Harrison's principles of internal medicine. - $18^{\text {th }}$ Ed.; 2012:19982014.

7. Ockene JK, Kuller LH, Svendsen KH, Meilahn E. The relationship of smoking cessation to coronary heart disease and lung cancer in the \{Multiple Risk Factor Intervention Trial (MRFIT) $\}$. Am J Public Heal. 1990;80(8):954-8.

8. Spinar J. Hypertension and Ischaemic Heart Disease. Cor Et Vasa. 2012.

9. Menotti A, Blackburn H, Kromhout D, Nissinen A, Fidanza F, Giampaoli S, et al. Changes in population cholesterol levels and coronary heart disease deaths in seven countries. Eur Hear J. 1997;18(4):566-71.

10. Garcia MJ, McNamara PM, Gordon T, Kannell WB. Morbidity and mortality in diabetics in the Framingham population. Sixteen year follow up study. Diabetes. 1974;23(2):105-11.
11. Frikke-Schmidt R, Nordestgaard BG, Jensen GB, Steffensen R, TybjrgHansen A. Genetic variation in ABCA1 predicts Ischaemic heart disease in the general population. Arterioscler Thromb Vasc Biol. 2008;28(1):180-6.

12. Kokkinos PF, Fernhall B. Physical activity and highdensity lipoprotein cholesterol levels: what is the relationship? Sports Med. 1999;28(5):307-14.

13. Phillips GB, Castelli WP, Abbott RD, McNamara PM. Association of hyperestrogenemia and coronary heart disease in men in the Framingham cohort. Am J Med. 1983 May;74(5):863-9.

14. Jenkins CD, Rosenman RH, Zyzanski SJ. Prediction of clinical coronary heart disease by a test for the coronary-prone behavior pattern. N Engl J Med. 1974 Jun 6;290(23):1271-5.

15. Roerecke M, Rehm J. Irregular heavy drinking occasions and risk of Ischaemic heart disease: a systematic review and meta-analysis. Am $\mathbf{J}$ Epidemiol. 2010 Mar 15;171(6):633-44.

16. Tanis BC, van den Bosch MA, Kemmeren JM, Cats VM, Helmerhorst FM, Algra A, et al. Oral contraceptives and the risk of myocardial infarction. N Engl J Med. 2001 Dec 20;345(25):1787-93.

17. Thomas Michel BBH. Goodman \& Gilman's pharmacological basis of therapeutics. - $12^{\text {th }} \mathrm{Ed}$.; 2011:745-788.

18. Dawalji S, Venkateshwarlu K, Thota S, Venisetty PK, Kumar R. Prescribing Pattern in Coronary Artery Disease: A Prospective Study. 2015;3:24-33.

19. Kumar M, Dahiya V, Mishra S, Sharma D, Mishra N, Lahkar M. Cardiovascular disease prevalence and drug utilization patterns at a tertiary care hospital in northeastern India. Int $\mathrm{J}$ Pharm Pharm Sci. 2016;8(6):116-9

20. George J, Devi P, Kamath DY, Anthony N, Kunnoor NS, Sanil SS. Patterns and determinants of cardiovascular drug utilization in coronary care unit patients of a tertiary care hospital. J Cardiovasc Dis Res. 2013;4(4):214-21.

21. Xavier D, Pais P, Devereaux PJ, Xie C, Prabhakaran D, Reddy KS, et al. Treatment and outcomes of acute coronary syndromes in India (CREATE): a prospective analysis of registry data. Lancet (London, England). 2008 Apr;371(9622):1435-42.

22. Classen DC, Pestotnik SL, Evans RS, Lloyd JF, Burke JP. Adverse drug events in hospitalized patients. Excess length of stay, extra costs, and attributable mortality. JAMA. 1997 Jan;277(4):301-6.

23. Pradeepa R, Mohan V. Hypertension \& prehypertension in developing countries. Indian $\mathrm{J}$ Med Res. 2008 Dec;128(6):688-90.

24. Rodgers A, Lawes C, MacMahon S. Reducing the global burden of blood pressure-related cardiovascular disease. J Hypertens Suppl. 2000 May;18(1):S3-6.

25. Ajay VS, Prabhakaran D. Coronary heart disease in Indians: Implications of the inter heart study. Indian $\mathbf{J}$ of Med Res. 2010;132:561-6. 
26. Balady GJ, Williams MA, Ades PA, Bittner V, Comoss P, Foody JM, et al. Core components of cardiac rehabilitation/secondary prevention programs: 2007 update: a scientific statement from the American Heart Association Exercise, Cardiac Rehabilitation, and Prevention Committee, the Council on Clinical Cardiology; the Councils O. Circulation. 2007 May;115(20):2675-82.

27. Banerjee S, Kumar V, Ramachandran PKA. Does the pharmacological management of unstable angina vary with age and gen der - a descriptive study. J Clin Diagnostic Res. 2010;(4):3150-7.

Cite this article as: Zachariah TG, Subramanyam K, Pooja M, Kempaller VJ. Drug utilization study in ischaemic heart disease in a tertiary care hospital, Mangalore, India. Int J Basic Clin Pharmacol 2017;6:1799-805 